\title{
Targeting TM4SF5 with anti-TM4SF5 monoclonal antibody suppresses the growth and motility of human pancreatic cancer cells
}

\author{
SANGKYU PARK ${ }^{1,2}$, DONGBUM KIM ${ }^{3}$, JEONG-A PARK ${ }^{1,2}$, HYUNG-JOO KWON $^{3,4}$ and YOUNGHEE LEE LE $^{1,2}$ \\ ${ }^{1}$ Department of Biochemistry, College of Natural Sciences; ${ }^{2}$ Biotechnology Research Institute, \\ Chungbuk National University, Cheongju, Chungbuk 28644; ${ }^{3}$ Center for Medical Science Research; ${ }^{4}$ Department of \\ Microbiology, College of Medicine, Hallym University, Chuncheon, Gangwon-do 24252, Republic of Korea
}

Received February 22, 2019; Accepted August 5, 2019

DOI: $10.3892 / \mathrm{ol} .2019 .11134$

\begin{abstract}
Pancreatic cancer is one of the most lethal cancers. Transmembrane 4 superfamily member 5 protein (TM4SF5) is one of the candidate molecular targets used for the prevention and treatment of TM4SF5-expressing cancers, including hepatocellular carcinoma, colon cancer and pancreatic cancer. Recently, a previous study reported the preventive effects of a peptide vaccine, which targeted TM4SF5, in a mouse pancreatic cancer model. The present study investigated the implication of TM4SF5 and the suppressive effect of anti-human TM4SF5 monoclonal antibody (anti-hTM4SF5 antibody) in human pancreatic cancer cell lines in vitro. Treatment with anti-hTM4SF5 antibody reduced cell viability, modulated the expression of EMT markers Vimentin and E-cadherin, and decreased cell motility in human pancreatic cancer cells that endogenously expressed TM4SF5. When TM4SF5 was exogenously overexpressed in the TM4SF5-negative cell line, the cells indicated increased cell viability and motility compared with control cells, and the phenotype was reversed by anti-hTM4SF5 antibody treatment. Therefore, the results of the current study demonstrated that the high expression of TM4SF5 is a tumorigenic factor in human pancreatic cells and anti-hTM4SF5 antibody treatment exhibits a suppressive effect in TM4SF5-expressing pancreatic cancer cells.
\end{abstract}

Correspondence to: Professor Younghee Lee, Department of Biochemistry, College of Natural Sciences, Chungbuk National University, 1 Chungdae-Ro Street, Cheongju, Chungbuk 28644, Republic of Korea

E-mail: yhl4177@cbnu.ac.kr

Abbreviations: EMT, epithelial-mesenchymal transition; HCC, hepatocellular carcinoma; PDAC, pancreatic ductal adenocarcinoma; TAA, tumor-associated antigen; TM4SF5, transmembrane 4 superfamily member 5 protein

Key words: transmembrane 4 superfamily member 5 protein, pancreatic cancer, antibody, anticancer activity, proliferation, motility

\section{Introduction}

According to the reports of National Cancer Institutes (USA), pancreatic cancer was the tenth and eleventh most prevalent case of cancer in men and women from 2010 to 2014 and the fourth leading cause of death from cancer in men and women from 2011 to 2015 . The case and death rates show an interesting tendency (1): Pancreatic cancer has a higher death rate than incidence rate. This is because early diagnosis is difficult, and the cancer is mostly found after it has already progressed to an advanced stage in many cases (2). Most pancreatic cancers are pancreatic ductal adenocarcinoma (PDAC) (3). Pancreatic cancer begins in minimally dysplastic epithelium and progresses to invasive carcinoma by accumulation of mutations; activation of KRAS oncogene, inactivation of tumor-suppressor genes such as CDKN2A and TP53, and deletion of SMAD4 (4).

Tetraspanins form protein complexes with other tetraspanins, integrins, and other membrane proteins, and the protein complexes form tetraspanin-enriched microdomains (TEM) by binding to membrane cholesterols and anchorage to the actin cytoskeleton (5). The tetraspanins are involved in regulation of cell differentiation, migration, proliferation, and tumor progression $(6,7)$. Transmembrane 4 superfamily member 5 (TM4SF5), one of the tetraspanins, was first reported in 1998, and the expression of TM4SF5 was reported in human cancer such as hepatocellular carcinoma (HCC), colon cancer, and pancreatic cancer $(8,9)$. The molecular function of TM4SF5 was intensively investigated in HCC (9-13). TM4SF5 induces the epithelial-mesenchymal transition (EMT), enhances translocation of $\mathrm{p} 27^{\mathrm{kip} 1}$ into cytosol, and reduces RhoA activity (9-11). The cytosolic p27 $7^{\mathrm{kip} 1}$ inhibits RhoA activity, and this leads to uncontrolled cell growth and tumorigenesis by loss of contact inhibition $(9,11)$. In addition, TM4SF5 accelerates G1/S phase by controlling cytosolic p $27^{\mathrm{kip} 1}$ and RhoA activity (12). TM4SF5 induces vascular endothelial growth factor (VEGF) expression and secretion, leading to an increase of angiogenic activity (13). On the other hand, treatment of the TM4SF5-targeted monoclonal antibody reverses cellular events induced by TM4SF5 expression; anti-TM4SF5 antibody induces translocation of $\mathrm{p} 27^{\mathrm{kip} 1}$ into nucleus, increased RhoA 
activity, reduced EMT, and suppression of tumor growth and metastasis $(10,14,15)$.

Since 1975, when the procedure of effectively producing monoclonal antibodies (mAbs) was developed (16), antibodies were used for imaging and therapy. In therapy, murine $\mathrm{mAb}$ triggered the stimulation of the patient's immune system. In the early 1990s, a technique for cloning IgG genes was developed and, as a result, IgG genes could be expressed in eukaryotic cells (17). This development of antibody technology has resulted in the production of antibodies such as chimeric antibodies and humanized antibodies (18). The chimeric antibodies include $70 \%$ of human sequences and the Fc portion is fully human. In order to humanize more of the parts of the murine $\mathrm{mAb}$, all parts except the complementarity-determining region (CDR) portion are replaced with human sequences. As a result, humanized antibodies include $85-90 \%$ of human sequences and have lower immune responses than chimeric antibodies (18). Anti-cancer therapy using mAb targeting surface antigens expressed on tumor cells is an efficacious strategy to treat cancer (19).

Previously, we found that TM4SF5-targeted monoclonal antibody and peptide vaccination has preventive and therapeutic effects on hepatocellular carcinoma and colon cancer models $(10,14,15,20,21)$. Regarding the implication of TM4SF5 as a target of anticancer strategy in pancreatic cancer, we revealed immunization with TM4SF5 peptide vaccine prevented tumor growth derived from TM4SF5-expressing mouse pancreatic cancer cells in an allograft mouse model (22). In this study, we confirmed the implication of TM4SF5 expression and anti-growth/motility effect of antibody targeting TM4SF5 in human pancreatic cancer cells.

\section{Materials and methods}

Cell culture. Mia-PaCa-2 and PANC-1 cells were maintained in Dulbecco's modified Eagle's media (DMEM; Hyclone) with $10 \%$ fetal bovine serum (FBS; Hyclone), $100 \mathrm{U} / \mathrm{ml}$ penicillin, and $100 \mu \mathrm{g} / \mathrm{ml}$ streptomycin at $37^{\circ} \mathrm{C}$ under a humidified atmosphere of $5 \% \mathrm{CO}_{2}$. ASPC-1, Capan-1, and Capan-2 cells were maintained in Roswell Park Memorial Institute medium (RPMI-1640; Hyclone) with 10\% FBS, $100 \mathrm{U} / \mathrm{ml}$ penicillin, and $100 \mu \mathrm{g} / \mathrm{ml}$ streptomycin. CFPAC-1 cells were maintained in Iscove's modified Dulbecco's medium (IMDM; Hyclone) with $10 \% \mathrm{FBS}, 100 \mathrm{U} / \mathrm{ml}$ penicillin, and $100 \mu \mathrm{g} / \mathrm{ml}$ streptomycin. H6c7 cells were maintained in Keratinocyte-SFM (Invitrogen; Thermo Fisher Scientific, Inc.) with $100 \mathrm{U} / \mathrm{ml}$ penicillin, and $100 \mu \mathrm{g} / \mathrm{ml}$ streptomycin.

Reverse transcription (RT) PCR. Total RNA was isolated with the TRI Reagent ${ }^{\circledR}$ according to the manufacturer's instructions (MRC). Then, $2 \mu \mathrm{g}$ of total RNA was reverse-transcribed in the first-strand synthesis buffer containing $6 \mu \mathrm{g} / \mathrm{ml}$ oligo(dT) primer, $50 \mathrm{U}$ M-MLV reverse transcriptase, $2 \mathrm{mM} \mathrm{dNTP}$, $10 \mathrm{mM}$ DTT, and $40 \mathrm{U}^{\mathrm{RNa} e O U T}{ }^{\mathrm{TM}}$ recombinant ribonuclease inhibitor (Invitrogen; Thermo Fisher Scientific, Inc.). The reaction was carried out at $37^{\circ} \mathrm{C}$ for $50 \mathrm{~min}$ and heat inactivated at $70^{\circ} \mathrm{C}$ for $15 \mathrm{~min}$. One microliter of the synthesized cDNA solution was subjected to a semi-quantitative PCR of 25 (for GAPDH) or 30 (for TM4SF5) cycles consisting of denaturation for $40 \mathrm{sec}$ at $95^{\circ} \mathrm{C}$, annealing for $40 \mathrm{sec}$ at $58^{\circ} \mathrm{C}$, and extension for $40 \mathrm{sec}$ at $72^{\circ} \mathrm{C}$. The primer sequences used were as follows: GAPDH, 5'-TCCACCACCCTGTTGCTGTA-3' (sense) and 5'-ACCACAGTCCATGCCATCAC-3' (anti-sense) (product size 452 bp); human TM4SF5, 5'-AGCTTGCAAGTC TGGCTCAT-3' (sense) and 5'-GCTGGATCCCACACAGTA CT-3' (anti-sense) (product size $401 \mathrm{bp}$ ).

Packaging and transduction of control and TM4SF5-encoding retroviruses. The human TM4SF5 cDNA was amplified from pcDNA3.1-hTM4SF5 (14) by PCR using the following primer set: hTM4SF5 5' primer, 5'-GAATTCGCCACCATGGAA CAAAAACTCATCTCAGAAGAGGATCTGGGTGCAATG TGTACGGGAAAA-3' and hTM4SF5 3' primer, 5'-CTC GAGTCAGTGAGGTGTGTCCTG-3'. The cDNA fragments were cloned into the expression vector pLXSN (Clontech Laboratories, Inc.) using the XhoI and EcoRI sites. GP2-293, a cell line derived from 293 cells, was obtained from Clontech and used as a packaging cell line for preparation of the retroviruses. GP2-293 cells were maintained in DMEM containing $10 \% \mathrm{FBS}$ in a $5 \% \mathrm{CO}_{2}$ incubator at $37^{\circ} \mathrm{C}$. Retroviral vectors pLXSN or pLXSN-hTM4SF5 along with pVSV-G (Clontech Laboratories, Inc.) encoding the pseudo-envelope protein gene were transfected into the cells using Lipofectamine 2000 (Invitrogen; Thermo Fisher Scientific, Inc.). Twelve hours later, the medium was exchanged with fresh culture medium supplemented with $10 \mathrm{mM}$ sodium butyrate (Sigma-Aldrich; Merck KGaA). After $48 \mathrm{~h}$, the supernatant of the culture medium was taken and filtrated through a filter with a $0.45 \mu \mathrm{m}$ pore size. The retrovirus supernatants were concentrated using Centricon centrifugal filters (Millipore) and stored at $-80^{\circ} \mathrm{C}$. The viral supernatant was applied to Mia-PaCa-2 cells along with $8 \mu \mathrm{g} / \mathrm{ml}$ of polybrene (Sigma-Aldrich; Merck KGaA). Twenty-four hours later, G418 (Sigma-Aldrich; Merck KGaA) was added at a concentration of $1 \mathrm{mg} / \mathrm{ml}$, and the G418-resistant transfected Mia-PaCa- 2 cells were selected by culture of the cells in the presence of G418 for 2 weeks.

Western blot analysis. Harvested cells were lysed in a lysis buffer (pH 8.0, 20 mM Tris- $\mathrm{HCl}, 137 \mathrm{mM} \mathrm{NaCl}, 10 \%$ glycerol, $10 \mathrm{mM}$ EDTA, $0.5 \%$ sodium deoxycholate, $0.1 \%$ SDS, $1 \%$ NP-40, protease inhibitor cocktail, and phosphatase inhibitor). Proteins were resolved by SDS-polyacrylamide gel electrophoresis and electro-transferred to polyvinylidene fluoride (PVDF) membranes (Millipore). The membranes were blocked with $5 \%$ dry milk in phosphate buffered saline-Tween-20 (PBS-T; 140 mM NaCl, 2.7 mM KCl, $10 \mathrm{mM}$ $\mathrm{Na}_{2} \mathrm{HPO}_{4}, 2 \mathrm{mM} \mathrm{KH} \mathrm{PO}_{4}$, and $0.05 \%$ Tween-20) and probed with an appropriate primary antibody. The monoclonal anti-GAPDH antibody was purchased from Santa Cruz Biotechnology, Inc. The anti-E-cadherin and anti-Vimentin polyclonal antibodies were purchased from Cell Signaling Technology, Inc. Immunoreactive proteins were visualized by horseradish peroxidase-conjugated anti-rabbit or anti-mouse secondary antibodies (Santa Cruz Biotechnology, Inc.) and an ECL solution (ATTO).

Humanized anti-hTM4SF5 monoclonal antibody. The humanized anti-hTM4SF5 monoclonal antibody (anti-hTM4SF5 antibody), hEC2-C-2, was established based on the mouse monoclonal antibody mEC2-C obtained by immunization with 
the cyclic peptide hTM4SF5EC2-C as an antigen (14). The anti-hTM4SF5 antibody recognizes structural epitope of the second extracellular loop region of TM4SF5. To obtain humanized antibody with intact IgG format, $\mathrm{VH}$ and $\mathrm{Vk}$ encoding genes originated from mEC2-C were synthesized (Bioneer). The synthesized genes were then inserted into the modified pcDNA 3.4 expression vector (Invitrogen; Thermo Fisher Scientific, Inc.) carrying the human IgG1 constant regions (CH1-hinge-CH2-CH3) or human kappa chain constant region (CL) for mammalian cell expression in HEK 293F cells. The antibodies were purified using Protein A affinity chromatography following the manufacturer's protocol after 5-7 days of cell culture.

Immunostaining and confocal microscopy. The cells were fixed with $4 \%$ paraformaldehyde and blocked with $3 \%$ BSA containing $0.1 \%$ Triton X-100. Cells were treated with anti-hTM4SF5 antibody ( $3 \mu \mathrm{g} / \mathrm{ml})$ for $3 \mathrm{~h}$. After extensive washing with PBS, the samples were incubated with Alexa Flour 488-conjugated goat anti-human IgG (Invitrogen; Thermo Fisher Scientific, Inc.) for $1 \mathrm{~h}$. The nuclei were stained with Hoechst 33258 (Sigma-Aldrich).

Immunoprecipitation. Whole cell lysates were lysed in a lysis buffer. After anti-hTM4SF5 antibody was conjugated to protein A-agarose beads (Roche Diagnostics), the whole cell lysates were immunoprecipitated with the antibody-conjugated agarose beads. Immunoprecipitated proteins were washed with PBS and processed for a standard western blot analysis using the mouse anti-hTM4SF5 monoclonal antibody (mEC2-CF, $1 \mu \mathrm{g} / \mathrm{ml}$ ), which we previously reported (23).

Cell proliferation assay. The cell proliferation ELISA, BrdU colorimetric kit (Roche Diagnostics), was used to measure the cell proliferation according to the manufacturer's instructions. Cells were treated with normal $\mathrm{IgG}$ or anti-hTM4SF5 antibody $(10 \mu \mathrm{g} / \mathrm{ml})$ for 3 days. The BrdU solution was added to each well, and then the plates were incubated for $4 \mathrm{~h}$ at $37^{\circ} \mathrm{C}$. After fixation of the cells, anti-BrdU antibody conjugated with peroxidase was added to each well for $90 \mathrm{~min}$ at room temperature. A colorimetric assay was developed with a substrate solution, and the absorbance at $370 \mathrm{~nm}$ with a reference wavelength of $492 \mathrm{~nm}$ was measured using a microplate reader (Bio-Rad Laboratories, Inc.).

In vitro wound-healing assay. Cells were placed in a 6-well plate, cultured overnight to $80 \sim 90 \%$ confluence in a medium containing serum, and the monolayer was wounded with a pipette tip (3 wounds/well). Normal IgG or anti-hTM4SF5 antibody $(10 \mu \mathrm{g} / \mathrm{ml})$ was added to the medium for the indicated periods. The cells were fixed with $4 \%$ paraformaldehyde (Biosesang) for $20 \mathrm{~min}$ and stained with $0.01 \%$ crystal violet (Sigma-Aldrich; Merck KGaA) for $20 \mathrm{~min}$. The wound-healing activity of cells was calculated by the following formula: The cells migrating into wound $(\%)=[$ (the wounded area at 0 day-cell-free space in the wounded area)/wounded area at 0 day $x 100]$. The percent ratio of migrated area to wounded area was measured at 3 points per each wound ( 9 points/well in total) under a microscope (Nikon).
In vitro cell migration and invasion assays. Trans-well chambers with $8 \mu \mathrm{m}$ porosity (Corning Incorporated) were used for these assays. For the migration assays, the lower side of the trans-well chamber membranes was coated with gelatin (10 $\mu \mathrm{g} /$ well; Sigma-Aldrich; Merck KGaA). For the invasion assays, a Matrigel invasion chamber (Corning Incorporated) was used. Cells were suspended in serum-free medium with normal IgG or anti-hTM4SF5 antibody $(10 \mu \mathrm{g} / \mathrm{ml})$ and placed on the top of the trans-well chamber. DMEM medium containing $10 \%$ FBS was placed in the lower chamber. After incubation for $48 \mathrm{~h}$, the cells that invaded the lower surface of the filters were fixed, stained with crystal violet, and counted under a microscope (Nikon). The migrated and invaded cells were calculated by the following formula: The migrated or invaded cells $(\%)=($ the total area-cell-free space in the total area)/the total area $\mathrm{x} 100$.

Statistics. The results are shown as the mean \pm standard error of the mean (SEM) from at least three independent experiments. Statistical significance of the differences between two samples was evaluated using Student's t-test. $\mathrm{P}<0.05$ was considered to indicate a statistically significant difference.

\section{Results}

Validation of the TM4SF5 expression in human pancreatic cancer cell lines. Previously, we checked TM4SF5 expression in human pancreatic cancer tissues by immunohistochemistry $(10,22)$. To validate the function of TM4SF5 in human pancreatic cancer cells, we first checked the mRNA levels of TM4SF5 in non-cancerous human pancreatic duct epithelial cell line H6c7 and several human pancreatic cancer cell lines such as ASPC-1, Capan-1, Capan-2, CFPAC-1, Mia-PaCa-2, and PANC-1 by RT-PCR. As shown in Fig. 1A, TM4SF5 mRNA was expressed in ASPC-1, Capan-1, Capan-2, and CFPAC-1 cells but barely expressed in Mia-PaCa-2, PANC-1, and H6c7 cells. Next, we investigated expression of TM4SF5 protein using immunostaining and confocal microscopy in Capan-2 and PANC-1 cells as a representative TM4SF5-positive and TM4SF5-negative cell line, respectively. In accordance with the mRNA expression, TM4SF5 protein was detected in Capan-2 cells but not in PANC-1 cells (Fig. 1B). Expression of TM4SF5 protein in the cells couldn't be verified by western blot analysis because the anti-TM4SF5 antibody has very low sensitivity when used for western blot analysis.

Suppression of human pancreatic cancer cell growth by treatment with the anti-hTM4SF5 antibody. The tetraspanins, including TM4SF5, regulates tumor growth and metastasis by interaction with integrins in HCC $(11,24-26)$. Previously, we confirmed that immunization with the TM4SF5 peptide vaccine suppressed growth of TM4SF5-expressing mouse pancreatic cancer cells in vivo (22). Therefore, we first checked the growth of TM4SF5-expressing human pancreatic cancer cells after treatment with anti-hTM4SF5 antibody interrupting the function of TM4SF5. To check the cell growth, we measured the proliferation rate of human pancreatic cancer cells using the BrdU incorporation assay. The proliferation rates were significantly decreased by the treatment with anti-hTM4SF5 antibody compared to normal IgG treatment 
A

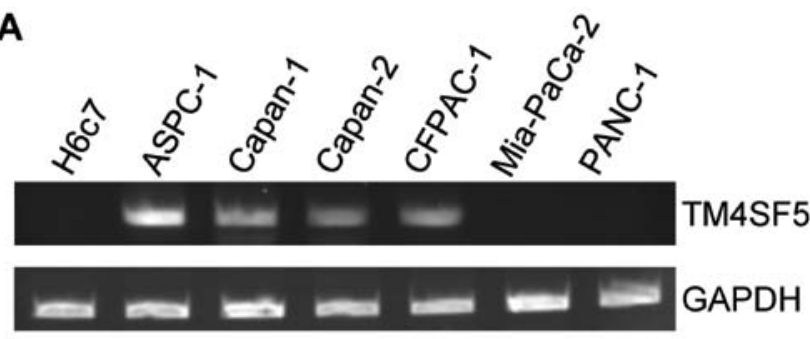

B
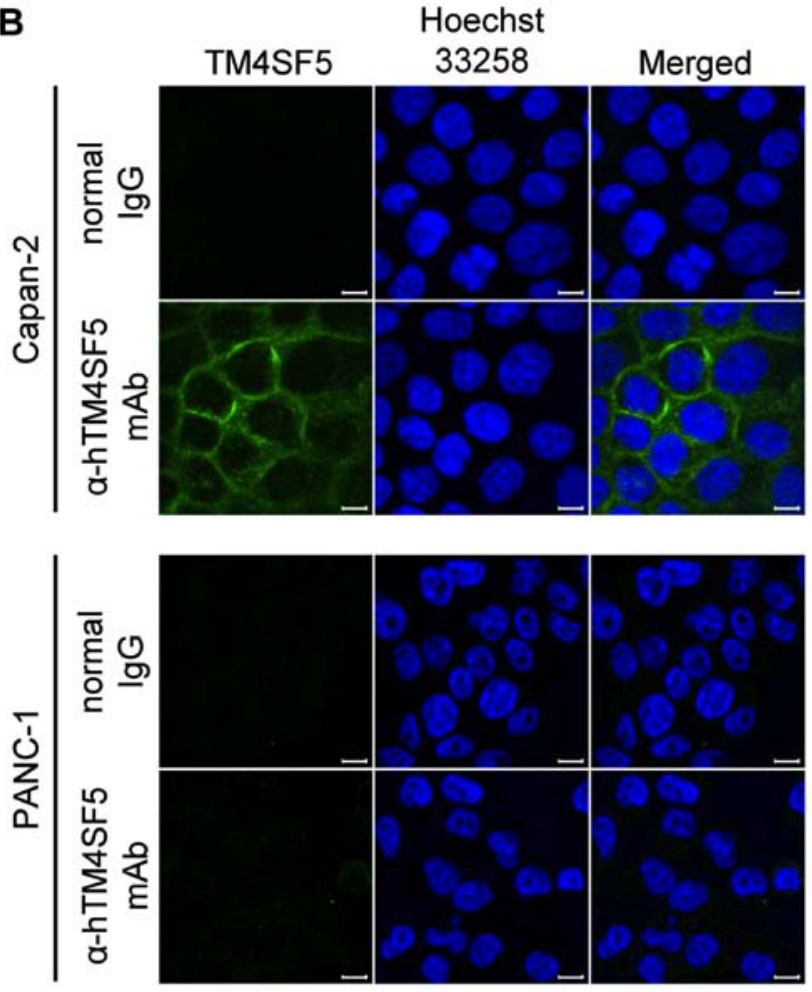

Figure 1. Validation of TM4SF5 expression in non-cancerous human pancreatic duct epithelial cells and human pancreatic cancer cells. (A) The expression of TM4SF5 mRNA was analyzed using RT-PCR. GAPDH was used as a loading control. (B) The expression of TM4SF5 protein was detected using immunostaining and confocal microscopy using humanized anti-hTM4SF5 monoclonal antibody (anti-hTM4SF5 mAb). Normal IgG was used as a control. Scale bar, $10 \mu \mathrm{m}$. TM4SF5, transmembrane 4 superfamily member 5 protein; RT, reverse transcription.

in TM4SF5-positive cell lines (ASPC-1, Capan-1, Capan-2, and CFPAC-1). However, there was no difference between the treatment groups in TM4SF5-negative cell lines (Mia-PaCa-2 and PANC-1) (Fig. 2). These data revealed that anti-hTM4SF5 antibody suppresses growth of TM4SF5-expressing human pancreatic cells.

Suppression of human pancreatic cancer cell motility by treatment with the anti-hTM4SF5 antibody. Previously, we reported that targeting of TM4SF5 inhibits motility of HCC and colon cancer cells in vitro and in vivo $(10,14,15)$. Therefore, we checked the motility of human pancreatic cancer cells using wound healing assay and transwell migration/invasion assay after treatment with the anti-hTM4SF5 antibody. As shown in Fig. 3A, the wound healing activity was significantly decreased by the treatment with the anti-hTM4SF5 antibody compared to normal IgG in the TM4SF5-positive cell line Capan-2. In contrast, the anti-hTM4SF5 antibody treatment had no effect in the TM4SF5-negative cell line PANC-1. The transwell migration and invasion activities were reduced by the anti-hTM4SF5 antibody treatment, but not by the normal IgG treatment, in Capan-2. However, anti-hTM4SF5 antibody had no effect in PANC-1 (Fig. 3B and C). Similar results were obtained in other TM4SF5-positive cell lines (ASPC-1 and CFPAC-1) and TM4SF5-negative cell line Mia-PaCa-2 (Fig. S1). Therefore, these results have shown that the anti-hTM4SF5 antibody inhibits the motility of TM4SF5-expressing pancreatic cancer cells in vitro.

Molecular change of EMT markers by anti-hTM4SF5 antibody treatment. In our previous studies, molecular levels of the EMT markers were changed by targeting TM4SF5 with antibody in HCC and colon cancer cells $(10,15)$. Therefore, we checked the expression of EMT markers after anti-hTM4SF5 antibody treatment in human pancreatic cancer cells. Vimentin and E-cadherin are mesenchymal and epithelial markers, respectively, and their levels of expression change during EMT $(27,28)$. In the TM4SF5-positive cell lines Capan-2 and ASPC-1, the expression level of E-cadherin was increased at 5 days after treatment with anti-hTM4SF5 antibody compared to the normal IgG (Fig. 4). Similar results were obtained in another TM4SF5-positive cell line CFPAC-1 (Fig. S2). In ASPC-1 cells, the expression level of Vimentin was decreased by the treatment with anti-hTM4SF5 antibody. There was no expression of Vimentin in Capan-2 (Fig. 4) and CFPAC-1 (Fig. S2) cells irrespective of antibody treatment. TM4SF5-negative cell lines PANC-1 (Fig. 4) and Mia-PaCa-2 (Fig. S2) did not express or only slightly expressed E-cadherin and commonly expressed Vimentin. The expression levels of E-cadherin and Vimentin were not changed by treatment with the anti-hTM4SF5 antibody or the normal IgG in the cells. These data suggest that the anti-hTM4SF5 antibody can inhibit EMT associated with tumor progression in TM4SF5-positive pancreatic cancer cells.

Establishment of the TM4SF5-overexpressing human pancreatic cancer cells. To validate the effects of TM4SF5 expression in human pancreatic cancer cells directly, we established a human pancreatic cancer cell line stably expressing TM4SF5 using TM4SF5-negative Mia-PaCa-2 cells. For exogenous expression of TM4SF5 in TM4SF5-negative pancreatic cancer cells, we used a retroviral system. We established control Mia-PaCa-2 cells transduced with the parental pLXSN vector (Mia-PaCa-2-mock) and TM4SF5-expressing Mia-PaCa-2 cells transduced with the recombinant vector pLXSN-hTM4SF5 (Mia-PaCa-2-hTM4SF5). To validate expression of TM4SF5, we detected TM4SF5 mRNA levels by RT-PCR (Fig. 5A). The TM4SF5 mRNA was detected in the clones A1 and A5 of Mia-PaCa-2-hTM4SF5 cells, but not in the clones of Mia-PaCa-2-mock cells. As we obtained similar results from the two clones, we further analyzed the clone A5 of Mia-PaCa-2-hTM4SF5 for the remaining investigation. The expression level of TM4SF5 protein was also checked by immunoprecipitation followed by western blot analysis (Fig. 5B). TM4SF5 protein was detected in the Mia-PaCa-2-hTM4SF5 cells, but not in the Mia-PaCa-2-mock cells. 

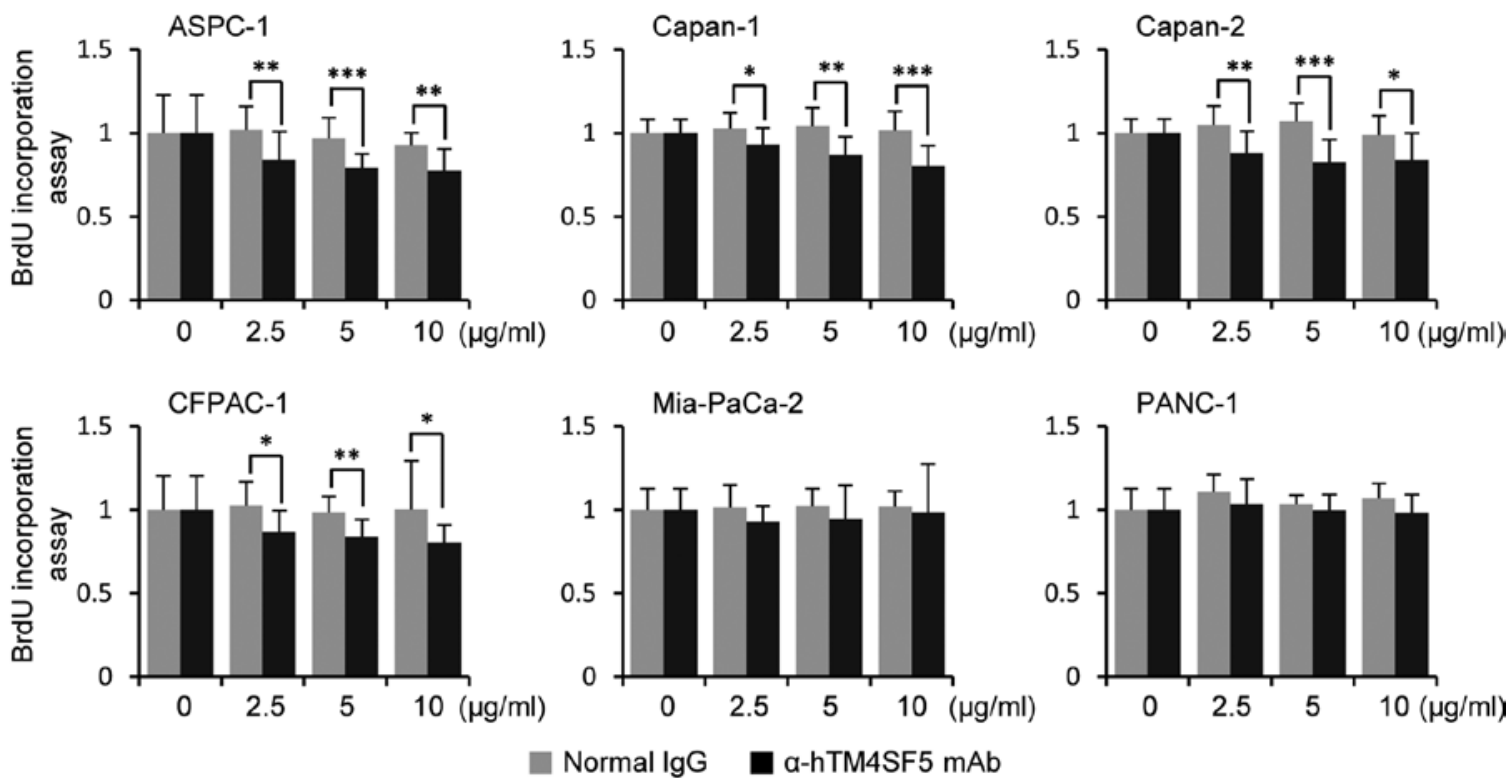

Figure 2. The effect of anti-hTM4SF5 mAb on the growth of human pancreatic cancer cells. Cell growth was measured using a BrdU incorporation assay. Values are the means \pm SEM. ${ }^{*} \mathrm{P}<0.05,{ }^{* *} \mathrm{P}<0.01,{ }^{* * * *} \mathrm{P}<0.005$ vs. each normal IgG control. TM4SF5, transmembrane 4 superfamily member 5 protein.

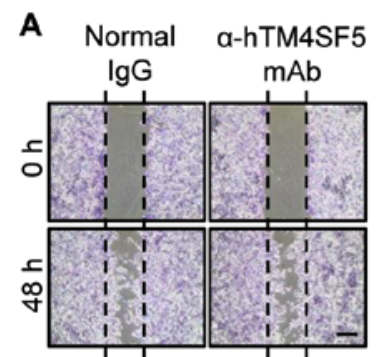

PANC-1

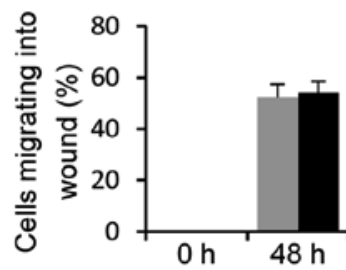

Normal $\operatorname{lgG}(10 \mu \mathrm{g} / \mathrm{ml})$
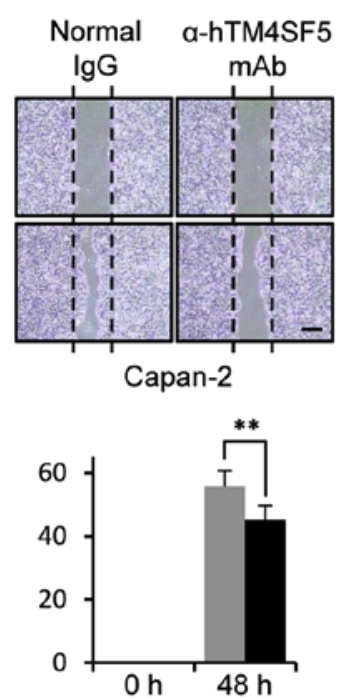

a-hTM4SF5 mAb $(10 \mu \mathrm{g} / \mathrm{ml})$
B
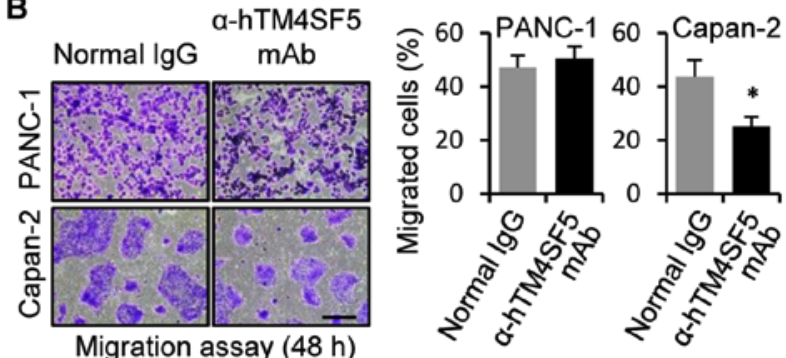

C
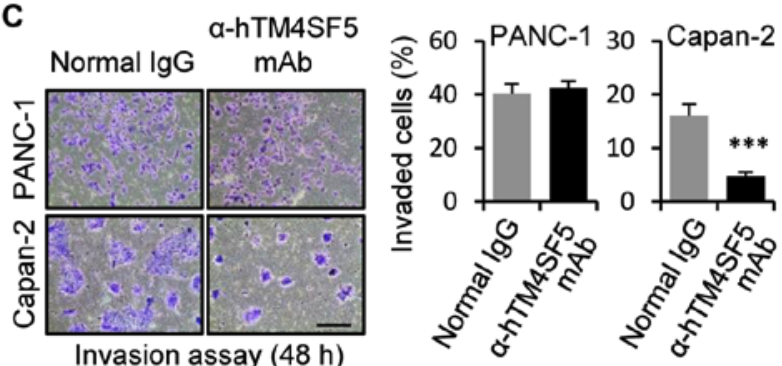

Figure 3. Motility change of human pancreatic cancer cells by anti-hTM4SF5 mAb treatment. The motility properties of Capan-2 and PANC-1 cells were compared after treatment with normal IgG or the anti-hTM4SF5 mAb. (A) Wound healing assay. A monolayer culture of Capan-2 and PANC-1 was wounded with a pipette tip, and the migration of cells into the wound area was examined at the indicated time points. Scale bar, $200 \mu \mathrm{m}$. (B) Migration and (C) invasion activity, the migrated and invaded cells on the lower sides of the transwell chambers were counted after incubation with the indicated materials. Scale bar, $100 \mu \mathrm{m}$. The percentage of wound healed, migrated or invaded cells was measured and compared. Values are the means $\pm \mathrm{SEM} .{ }^{*} \mathrm{P}<0.05,{ }^{* * *} \mathrm{P}<0.01,{ }^{* * *} \mathrm{P}<0.005$ vs. normal IgG control. TM4SF5, transmembrane 4 superfamily member 5 protein.

To analyze the cellular change induced by TM4SF5 expression, we checked cell growth and motility of the Mia-PaCa-2-hTM4SF5 and Mia-PaCa-2-mock cells. First, we measured the change of cell growth using a BrdU incorporation assay. The cell growth was increased in Mia-PaCa-2-hTM4SF5 cells compared to Mia-PaCa-2-mock cells (Fig. 5C). Next, we measured the change of cell motility using a wound healing assay and a transwell migration/invasion chamber. The cell migration into the wound area was increased in Mia-PaCa-2-hTM4SF5 cells compared to Mia-PaCa-2-mock cells (Fig. 5D), and the rate of cell migration and invasion through the transwell chamber also increased in Mia-PaCa-2-hTM4SF5 cells (Fig. 5E). Therefore, we conclude that expression of TM4SF5 enhanced cell growth and motility in human pancreatic cancer cells.

Suppression of cell growth and motility by anti-hTM4SF5 antibody treatment in TM4SF5-overexpressing pancreatic cancer cells. To check whether the down-regulation of cell proliferation and motility by the treatment with 

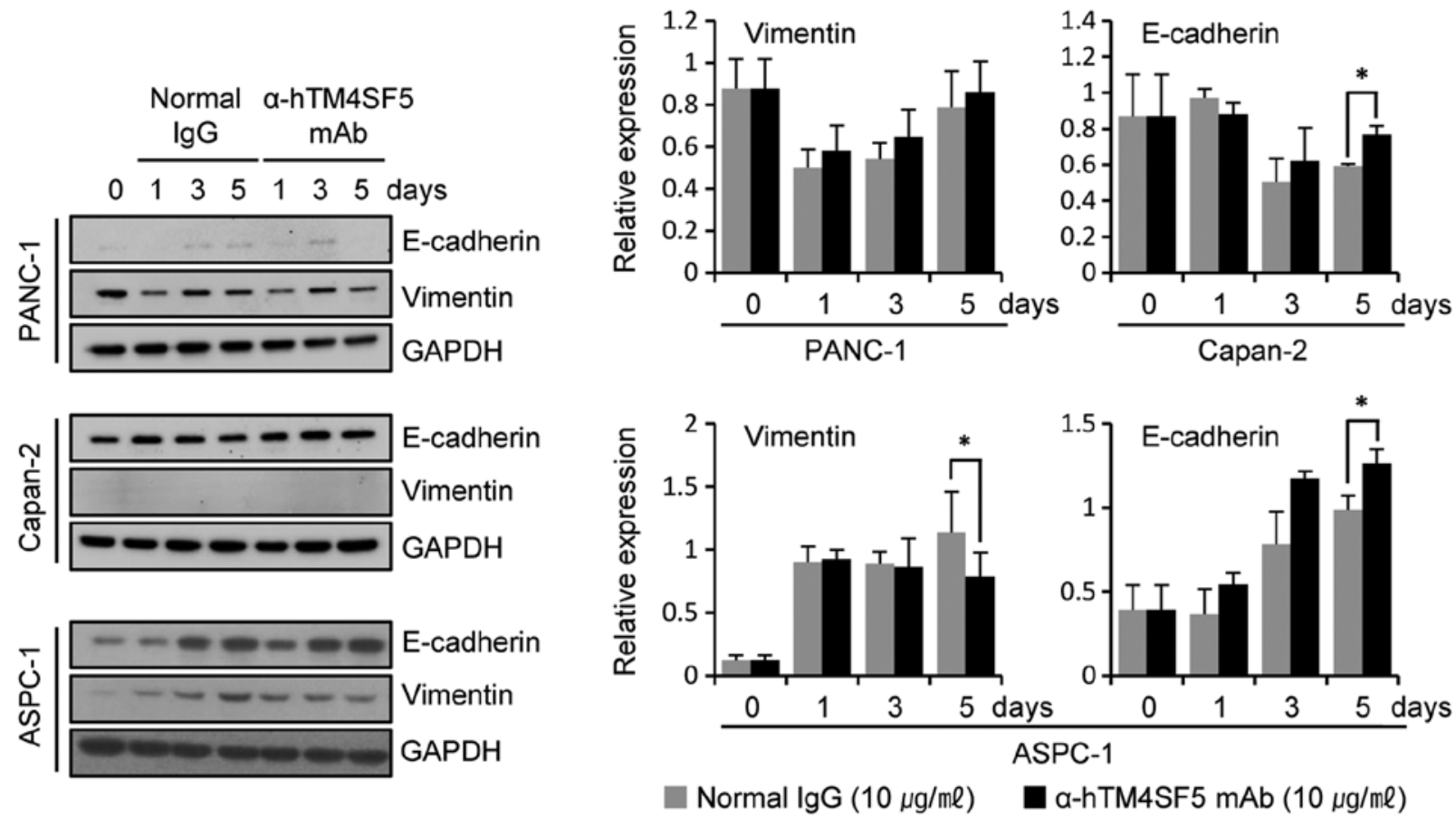

Figure 4. Changes in EMT marker expression in human pancreatic cancer cells after anti-hTM4SF5 mAb treatment. The expression of E-cadherin and Vimentin in Capan-2, PANC-1, and ASPC-1 cells were analyzed using western blot analysis after treatment with normal IgG or the anti-hTM4SF5 mAb at the indicated time points. The relative intensities of E-cadherin and Vimentin bands are indicated as a graph after normalization with GAPDH. P-values are evaluated using a ratio paired t-test. Values are the means \pm SEM. " $\mathrm{P}<0.05$ vs. normal IgG control. EMT, epithelial-mesenchymal transition; TM4SF5, transmembrane 4 superfamily member 5 protein.

A

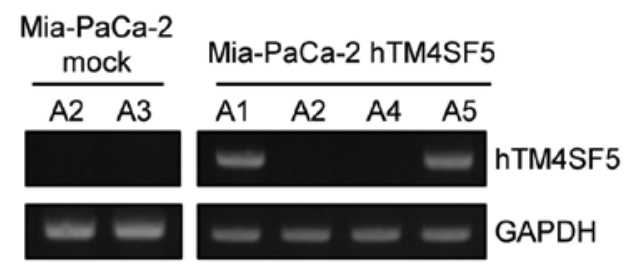

D

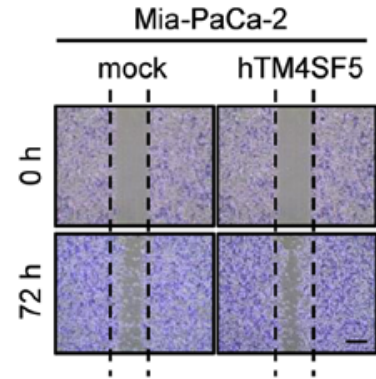

Mia-PaCa-2 mock

Mia-PaCa-2 hTM4SF5

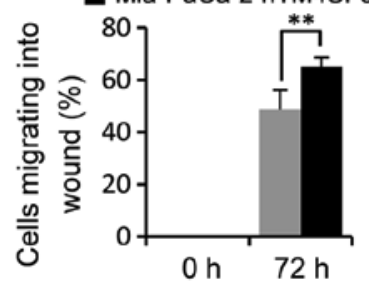

B

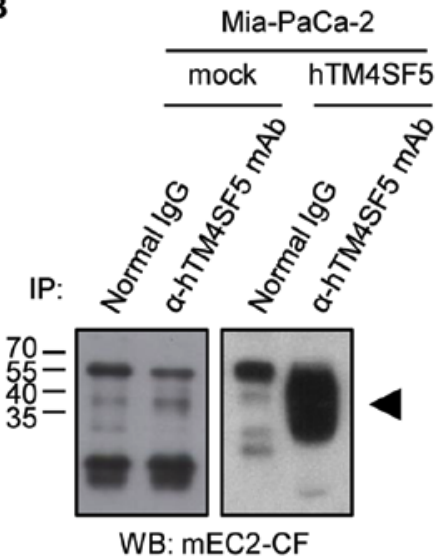

C Mia-PaCa-2 mock

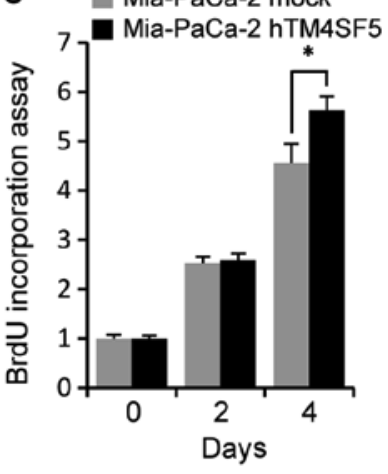

E

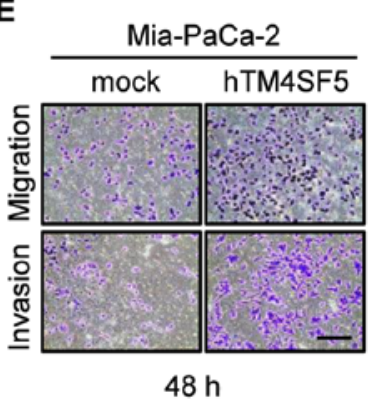

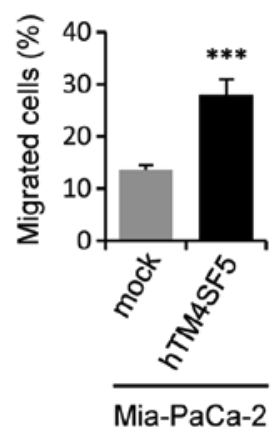

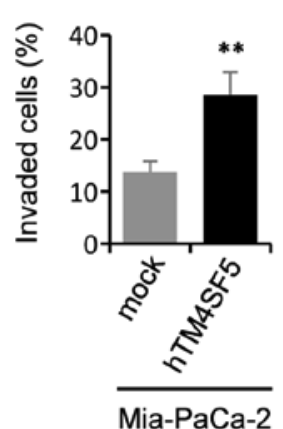

Figure 5. Establishment and characterization of TM4SF5-overexpressing human pancreatic cancer cells. (A) The expression of TM4SF5 mRNA in cells was determined using RT-PCR. GAPDH was used as a loading control. (B) The expression levels of TM4SF5 protein in cells were verified by immunoprecipitation and western blot analysis using the humanized anti-hTM4SF5 mAb (hEC2-C-2) and mouse anti-hTM4SF5 monoclonal antibody (mEC2-CF). Arrow head, TM4SF5. (C) The cell growth was measured using a BrdU incorporation assay. (D) Wound healing assay. Scale bar, $200 \mu \mathrm{m}$. (E) The migratory and invasive properties. The percentage of wound healed, migrated or invaded cells was measured and compared. Values are the means \pm SEM. ${ }^{*} \mathrm{P}<0.05,{ }^{* *} \mathrm{P}<0.01$, ${ }^{* * *} \mathrm{P}<0.005$ vs. Mia-PaCa-2-mock. TM4SF5, transmembrane 4 superfamily member 5 protein; RT, reverse transcription. 
anti-hTM4SF5 antibody observed in human pancreatic cancer cells naturally expressing TM4SF5 (Figs. 2-4) also occurs in TM4SF5-overexpressing pancreatic calls, we measured cell proliferation and motility after treatment with anti-hTM4SF5 antibody in the Mia-PaCa-2-hTM4SF5 cells. First, we measured the cell proliferation using a BrdU incorporation assay. The cell proliferation was significantly reduced in the Mia-PaCa-2-hTM4SF5 cells by treatment with anti-hTM4SF5 antibody compared to normal $\mathrm{IgG}$ but was not changed in the Mia-PaCa-2-mock cells (Fig. 6). Next, we measured migration activity. As shown in Fig. 7A, the wound healing activity was decreased by the anti-hTM4SF5 antibody treatment compared to the normal IgG treatment in the Mia-PaCa-2-TM4SF5 cells. The rate of migration/invasion was also decreased by anti-hTM4SF5 antibody treatment compared to the normal IgG control in the Mia-PaCa-2-hTM4SF5 cells (Fig. 7B and C). However, there was no difference induced by the antibody treatment in Mia-PaCa-2-mock cells. These results show that anti-hTM4SF5 antibody reduced cell proliferation and motility of the TM4SF5-overexpressing pancreatic cancer cells as it reduced these parameters of the TM4SF5-positive pancreatic cancer cells.

Modified expression of EMT markers after anti-hTM4SF5 antibody treatment in TM4SF5-overexpressing pancreatic cancer cells. Because the cell motility was increased by TM4SF5 transduction (Fig. 5D and E) and decreased by anti-hTM4SF5 antibody treatment in the TM4SF5overexpressing pancreatic cancer cells (Fig. 7), we next checked whether expression of EMT markers (E-cadherin and Vimentin) in the TM4SF5-overexpressing pancreatic cancer cells was changed after anti-hTM4SF5 antibody treatment. The expression level of Vimentin was decreased by anti-hTM4SF5 antibody treatment in the Mia-PaCa-2-hTM4SF5 cells compared to normal IgG treatment. In contrast, the Vimentin expression level was not changed in Mia-PaCa-2-mock cells by anti-hTM4SF5 antibody treatment. The E-cadherin was not detected in Mia-PaCa-2-mock and Mia-PaCa-2-hTM4SF5 cells (Fig. 8). These data suggest that anti-hTM4SF5 antibody can influence mesenchymal-epithelial transition (MET) in a TM4SF5-overexpressing human pancreatic cancer cell model.

\section{Discussion}

Previously, we found that TM4SF5 can be a target for therapy and prevention of HCC and colon cancer $(10,14,15,20,21)$. Ahn et al also produced TM4SF5-targeted chimeric antibodies using phage display method and showed that TM4SF5-targeting antibodies had anti-cancer activity in TM4SF5-expressing HCC and colon cancer (29). Because expression of TM4SF5 in pancreatic cancer was previously reported $(8,10)$, here we investigated expression and function of TM4SF5 in human pancreatic cancer cell lines and confirmed anti-cancer effects of the antibody targeting TM4SF5 on TM4SF5-expressing cells to evaluate its possible application to pancreatic cancer.

Treatment of TM4SF5-expressing human pancreatic cancer cells with anti-hTM4SF5 antibody significantly suppressed cell growth (Figs. 2 and 6) and motility (Figs. 3, 7 and S1).
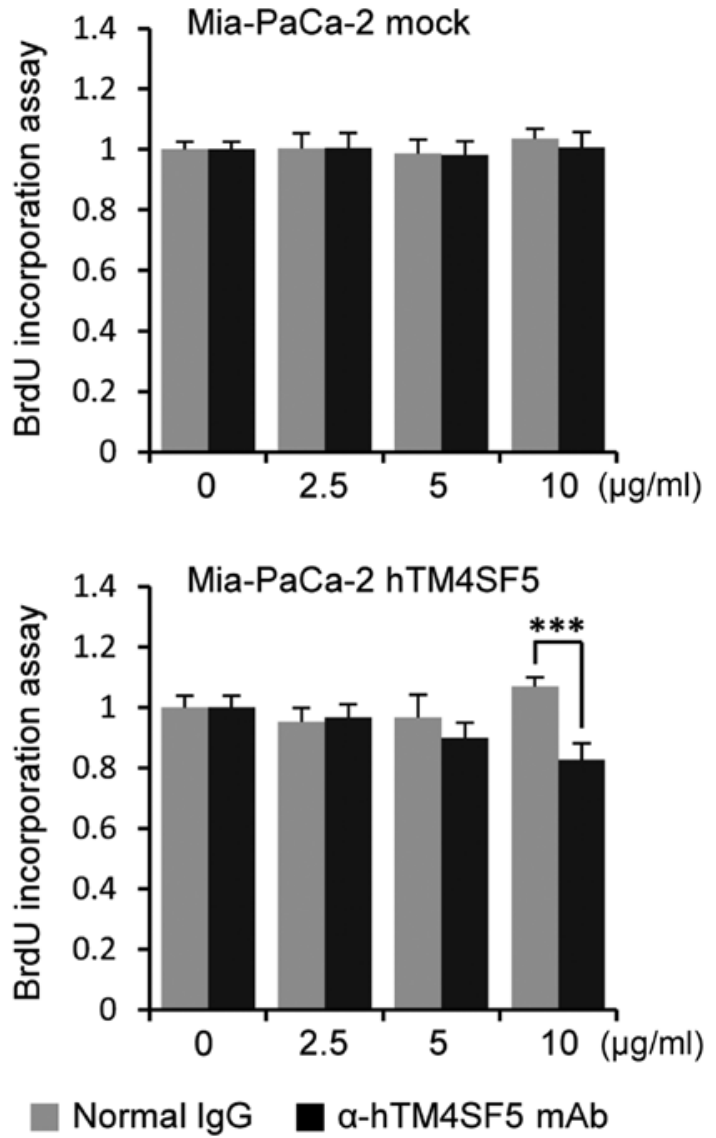

Figure 6. The effect of anti-hTM4SF5 mAb on the growth of TM4SF5-overexpressing human pancreatic cancer cells. The cell growth was measured using a BrdU incorporation assay. Values are the means \pm SEM. ${ }^{* * *} \mathrm{P}<0.005$ vs. each normal IgG control. TM4SF5, transmembrane 4 superfamily member 5 protein.

Furthermore, the expression of EMT markers was changed by treatment of anti-hTM4SF5 antibody (Figs. 4, 8 and S2). Taken together, these results show that high expression of TM4SF5 can endow the human pancreatic cells with oncogenic properties and that anti-hTM4SF5 antibody has therapeutic effects in pancreatic cancer cells, suggesting possible application of the anti-hTM4SF5 antibody in treating pancreatic cancer. From a practical perspective, the anti-hTM4SF5 antibody can be applied to antibody-drug conjugates (ADC). The use of ADCs is an emerging strategy for anticancer therapy that combines antibody-mediated targeted treatment with cytotoxic chemotherapy drugs (30). The ADCs induce specific targeting and therapeutic effects through antibody-dependent cellular cytotoxicity (ADCC) or complement-dependent cytotoxicity (CDC) (31).

E-cadherin and Vimentin are typical EMT markers. Loss of E-cadherin expression induced or contributed to drug resistance of colon cancer and breast cancer $(32,33)$. In addition, Vimentin expression was shown to be involved in the drug resistance of colon cancer (34). EMT marker expression is correlated with conventional drug resistance also in pancreatic cancer cells, and suppression of mesenchymal marker ZEB-1 induces an increase of E-cadherin and overcoming of drug resistance $(35,36)$. Based on our results, E-cadherin was not or very weakly detected in PANC-1 and Mia-PaCa-2, and Vimentin was not or very 
A
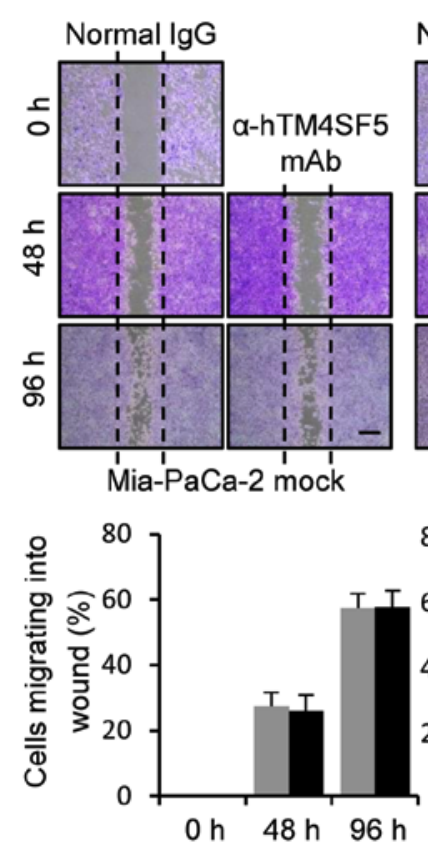

Normal $\operatorname{lgG}(10 \mu \mathrm{g} / \mathrm{ml})$
Normal lgG
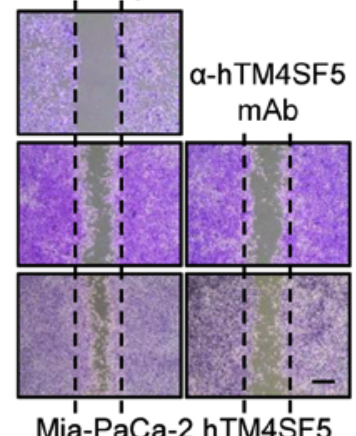

Mia-PaCa-2 hTM4SF5

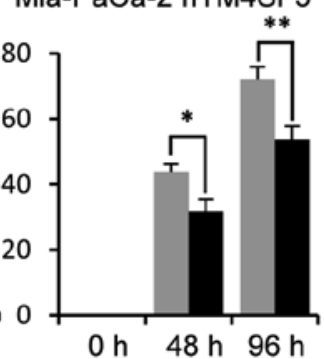

a-hTM4SF5 mAb $(10 \mu \mathrm{g} / \mathrm{ml})$
B
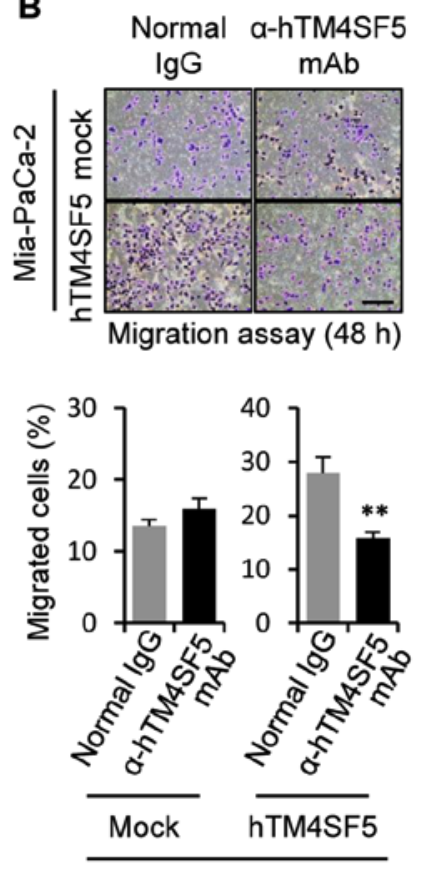

Mia-PaCa-2
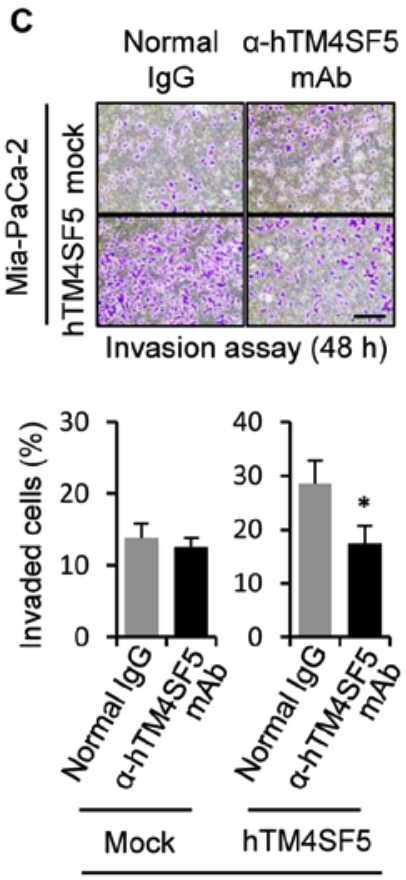

Mia-PaCa-2

Figure 7. Motility change of TM4SF5-overexpressing human pancreatic cancer cells by the anti-hTM4SF5 mAb treatment. The motility properties of the Mia-PaCa-2-mock and Mia-PaCa-2-hTM4SF5 cells were compared after treatment with normal IgG or the anti-hTM4SF5 mAb. (A) Wound healing assay. Scale bar, $200 \mu \mathrm{m}$. (B) Migratory and (C) invasive properties. Scale bar, $100 \mu \mathrm{m}$. The percentage of wound healed, migrated or invaded cells was measured and compared. Values are the means \pm SEM. ${ }^{*} \mathrm{P}<0.05,{ }^{* *} \mathrm{P}<0.01$ vs. normal IgG control. TM4SF5, transmembrane 4 superfamily member 5 protein.

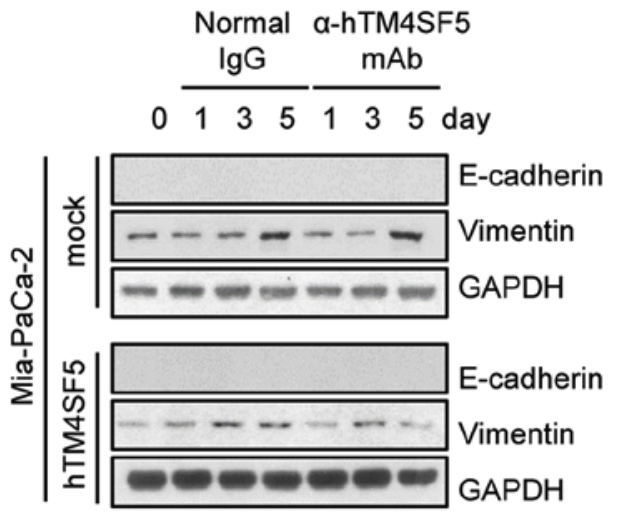

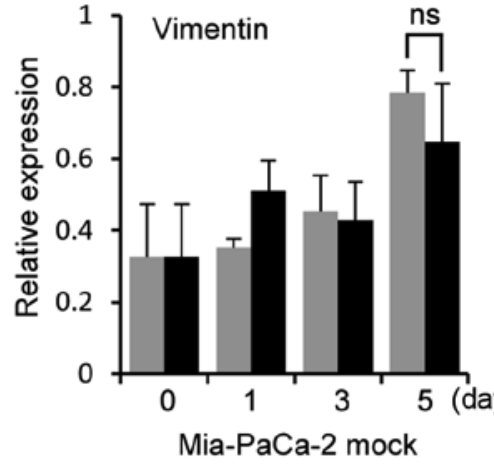

Normal $\lg G(10 \mu \mathrm{g} / \mathrm{ml})$

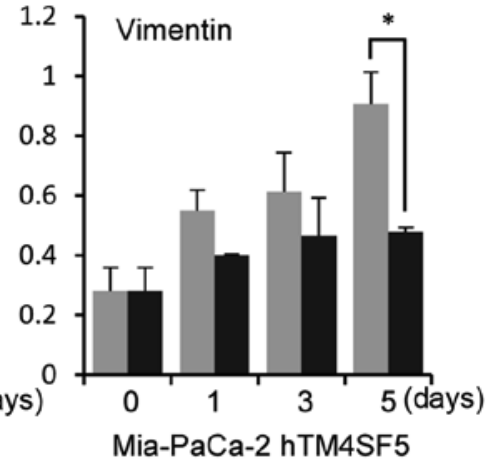

a-hTM4SF5 mAb $(10 \mu \mathrm{g} / \mathrm{ml})$

Figure 8. Change of EMT marker expression in TM4SF5-overexpressing human pancreatic cancer cells after the anti-hTM4SF5 mAb treatment. The expression levels of E-cadherin and Vimentin were analyzed using western blot analysis at the indicated time points after treatment with normal IgG or the anti-hTM4SF5 mAb. GAPDH was used as a loading control. Values are the means \pm SEM. ${ }^{*}$ P $<0.05$ vs. normal IgG control. EMT, epithelial-mesenchymal transition; TM4SF5, transmembrane 4 superfamily member 5 protein.

weakly detected in Capan-2 and CFPAC-1. These expression patterns in these cell lines have been reported by many groups and are associated with cellular phenomenon (37-41). In terms of anti-cancer drug resistance, anti-cancer drug sensitive cells (BxPC-3, HPAC, ASPC-1, and CFPAC-1) expressed E-cadherin, whereas the less sensitive cells (PANC-1 and Mia-PaCa-2) expressed Vimentin (39). In terms of invasive properties, E-cadherin was expressed in low invasive cells such as BxPC-3, CFPAC-1, and SW1990, and Vimentin was expressed in highly-invasive cells such as PaTu8988 (37). In addition, E-cadherin was expressed in cells showing epithelial characteristics (Capan-2 and
BxPC-3), and Vimentin was expressed in mesenchymal-like cells (Mia-PaCa-2) in terms of cell shape (41). Based on our investigation, all the TM4SF5-expressing cells we examined in detail (ASPC-1, Capan-2, and CFPAC-1) expressed E-cadherin. Furthermore, the TM4SF5-positive cells were responsive to the suppressive effects of anti-TM4SF5 antibody. Considering regulation of EMT marker expression by the anti-hTM4SF5 antibody (Figs. 4 and 8) and correlation between drug resistance and EMT properties, the anti-hTM4SF5 antibody treatment may enhance the efficacy of anti-cancer reagent in chemotherapy of pancreatic cancer patients. 
For the treatment of pancreatic ductal adenocarcinoma (PDAC), Gemcitabine has been considered a first-line therapy. However, gemcitabine treatment provides only a slight effect and consequently the overall survival of patients is approximately 6 months (42). Therefore, investigators have explored various therapeutic strategies including the use of therapeutic antibodies (43-45). Various therapeutic antibody candidates bind to different targets: Cetucimab, anti-EGFR chimeric antibody (46); trastuzumab, humanized anti-ErbB2/HER2 antibody (47); tigatuzumab, humanized anti-death receptor 5 antibody (48); cixutumumab, anti-IGF-1R antibody (49); bevacizumab, humanized anti-VEGF-A antibody (50), and so on. The antibodies have been studied and used in clinical trials to treat pancreatic cancer $(43-45,51)$. Despite these attempts, the clinical trials did not show adequate clinical outcomes, and pancreatic cancer remains a lethal disease. Therefore, continuous investigation and new target discovery are needed for the treatment of pancreatic cancer. Previously, we suggested TM4SF5 as an anti-cancer target of pancreatic cancer because vaccination with TM4SF5 peptide vaccine suppressed growth of TM4SF5-expressing tumors in a mouse pancreatic cancer model (22). However, the effect of peptide vaccine may have limitations because of low antigenicity and tumor heterogeneity (52). Therefore, therapeutic antibodies, which can be evaluated in detail and applied promptly in necessity, may have advantages in the aspect of practical application. Therefore, it was required to investigate the efficacy of the anti-hTM4SF5 antibody using human pancreatic cancer cells. In this study, we found that treatment of the anti-hTM4SF5 antibody suppressed the growth and motility of TM4SF5-expressing pancreatic cancer cells. In addition, TM4SF5 expression induced growth and motility of pancreatic tumor cells. Although effectiveness and safety of anti-TM4SF5 antibody in vivo have to be tested using animal model in the future, we believe that our approach and results may respectively provide a novel strategy and useful information to treat pancreatic cancer.

\section{Acknowledgements}

Not applicable.

\section{Funding}

The current study was supported by grants from the National Research Foundation (grant nos. NRF-2015R1A2A2A01007 209 and NRF-2018R1A2B6002504) funded by the Ministry of Science and ICT in the Republic of Korea.

\section{Availability of data and materials}

All data generated or analyzed during this study are included in this published article.

\section{Authors' contributions}

SP, HJK and YL conceived the study and its design, and wrote the manuscript. SP and JAP performed experiments including PCR, cell line establishment, proliferation assays, migration assays and western blot analysis. DK performed immunostaining and confocal analysis. All authors have read and approved the final manuscript.

\section{Ethics approval and consent to participate}

Not applicable.

\section{Patient consent for publication}

Not applicable.

\section{Competing interests}

The authors declare that they have no competing interests.

\section{References}

1. Negoita S, Feuer EJ, Mariotto A, Cronin KA, Petkov VI, Hussey SK, Benard V, Henley SJ, Anderson RN, Fedewa S, et al: Annual report to the nation on the status of cancer, part II: Recent changes in prostate cancer trends and disease characteristics. Cancer 124: 2801-2814, 2018.

2. Ansari D, Tingstedt B, Andersson B, Holmquist F, Sturesson C, Williamsson C, Sasor A, Borg D, Bauden M and Andersson R: Pancreatic cancer: Yesterday, today and tomorrow. Future Oncol 12: 1929-1946, 2016.

3. Ryan DP, Hong TS and Bardeesy N: Pancreatic adenocarcinoma. N Engl J Med 371: 2140-2141, 2014.

4. Hidalgo M: Pancreatic cancer. N Engl J Med 362: 1605-1617, 2010.

5. Yáñez-Mó M, Barreiro O, Gordon-Alonso M, Sala-Valdés M and Sánchez-Madrid F: Tetraspanin-enriched microdomains: A functional unit in cell plasma membranes. Trends Cell Biol 19: 434-446, 2009

6. Anderson KR, Singer RA, Balderes DA, Hernandez-Lagunas L, Johnson CW, Artinger KB and Sussel L: The L6 domain tetraspanin Tm4sf4 regulates endocrine pancreas differentiation and directed cell migration. Development 138: 3213-3224, 2011.

7. Richardson MM, Jennings LK and Zhang XA: Tetraspanins and tumor progression. Clin Exp Metastasis 28: 261-270, 2011.

8. Müller-Pillasch F, Wallrapp C, Lacher U, Friess H, Büchler M, Adler G and Gress TM: Identification of a new tumour-associated antigen TM4SF5 and its expression in human cancer. Gene 208: 25-30, 1998.

9. Lee SA, Lee SY, Cho IH, Oh MA, Kang ES, Kim YB, Seo WD, Choi S, Nam JO, Tamamori-Adachi M, et al: Tetraspanin TM4SF5 mediates loss of contact inhibition through epithelial-mesenchymal transition in human hepatocarcinoma. J Clin Invest 118: 1354-1366, 2008.

10. Kwon S, Choi KC, Kim YE, Ha YW, Kim D, Park BK, Wu G, Kim DS, Lee Y and Kwon HJ: Monoclonal antibody targeting of the cell surface molecule TM4SF5 inhibits the growth of hepatocellular carcinoma. Cancer Res 74: 3844-3856, 2014.

11. Lee JW: TM4SF5-mediated protein-protein networks and tumorigenic roles. BMB Rep 47: 483-487, 2014.

12. Kim H, Kang M, Lee SA, Kwak TK, Jung O, Lee HJ, Kim SH and Lee JW: TM4SF5 accelerates G1/S phase progression via cytosolic p27Kip1 expression and RhoA activity. Biochim Biophys Acta 1803: 975-982, 2010.

13. Choi S, Lee SA, Kwak TK, Kim HJ, Lee MJ, Ye SK, Kim SH, Kim S and Lee JW: Cooperation between integrin alpha5 and tetraspan TM4SF5 regulates VEGF-mediated angiogenic activity. Blood 113: 1845-1855, 2009.

14. Wu G, Kim D, Park BK, Park S, Ha JH, Kim TH, Gautam A, Kim JN, Lee SI, Park HB, et al: Anti-metastatic effect of the TM4SF5-specific peptide vaccine and humanized monoclonal antibody on colon cancer in a mouse lung metastasis model. Oncotarget 7: 79170-79186, 2016.

15. Kim YE, Kwon S, Wu G, Kim D, Park BK, Park JA, Choi KC, Kim DS, Kwon HJ and Lee Y: Therapeutic effect of a TM4SF5-specific monoclonal antibody against colon cancer in a mouse model. Oncotarget 5: 8402-8415, 2014. 
16. Köhler G and Milstein C: Continuous cultures of fused cells secreting antibody of predefined specificity. Nature 256: 495-497, 1975.

17. Winter G and Milstein C: Man-made antibodies. Nature 349: 293-299, 1991.

18. Chames P, Van Regenmortel M, Weiss E and Baty D: Therapeutic antibodies: Successes, limitations and hopes for the future. $\mathrm{Br}$ J Pharmacol 157: 220-233, 2009.

19. Weiner LM, Murray JC and Shuptrine CW: Antibody-based immunotherapy of cancer. Cell 148: 1081-1084, 2012.

20. Kwon S, Kim D, Park BK, Cho S, Kim KD, Kim YE, Park CS, Ahn HJ, Seo JN, Choi KC, et al: Prevention and therapy of hepatocellular carcinoma by vaccination with TM4SF5 epitopeCpG-DNA-liposome complex without carriers. PLoS One 7: e33121, 2012.

21. Kwon S, Kim YE, Kim D, Park BK, Wu G, Kim TH, Choi SH Kim DS, Kwon HJ and Lee Y: Prophylactic effect of a peptide vaccine targeting TM4SF5 against colon cancer in a mouse model. Biochem Biophys Res Commun 435: 134-139, 2013.

22. Park S, Kim D, Wu G, Jung H, Park JA, Kwon HJ and Lee Y: A peptide-CpG-DNA-liposome complex vaccine targeting TM4SF5 suppresses growth of pancreatic cancer in a mouse allograft model. OncoTargets Ther 11: 8655-8672, 2018.

23. Park BK, Park JY, Kim TH, Kim D, Wu G, Gautam A Maharjan S, Lee SI, Lee Y, Kwon HJ and Choi KC: Production of an anti-TM4SF5 monoclonal antibody and its application in the detection of TM4SF5 as a possible marker of a poor prognosis in colorectal cancer. Int J Oncol 53: 275-285, 2018.

24. Detchokul S, Williams ED, Parker MW and Frauman AG: Tetraspanins as regulators of the tumour microenvironment: Implications for metastasis and therapeutic strategies. $\mathrm{Br}$ J Pharmacol 171: 5462-5490, 2014.

25. Vences-Catalán F, Rajapaksa R, Srivastava MK, Marabelle A, Kuo CC, Levy R and Levy S: Tetraspanin CD81 promotes tumor growth and metastasis by modulating the functions of $\mathrm{T}$ regulatory and myeloid-derived suppressor cells. Cancer Res 75: 4517-4526, 2015.

26. Zijlstra A, Lewis J, Degryse B, Stuhlmann H and Quigley JP: The inhibition of tumor cell intravasation and subsequent metastasis via regulation of in vivo tumor cell motility by the tetraspanin CD151. Cancer Cell 13: 221-234, 2008.

27. Liu CY, Lin HH, Tang MJ and Wang YK: Vimentin contributes to epithelial-mesenchymal transition cancer cell mechanics by mediating cytoskeletal organization and focal adhesion maturation. Oncotarget 6: 15966-15983, 2015.

28. Tian X, Liu Z, Niu B, Zhang J, Tan TK, Lee SR, Zhao Y, Harris DC and Zheng G: E-cadherin/ $\beta$-catenin complex and the epithelial barrier. J Biomed Biotechnol 2011: 567305, 2011.

29. Ahn HM, Ryu J, Song JM, Lee Y, Kim HJ, Ko D, Choi I Kim SJ, Lee JW and Kim S: Anti-cancer activity of novel TM4SF5-targeting antibodies through TM4SF5 neutralization and immune cell-mediated cytotoxicity. Theranostics 7: 594-613, 2017.

30. Diamantis $\mathrm{N}$ and Banerji U: Antibody-drug conjugates-an emerging class of cancer treatment. Br J Cancer 114: 362-367, 2016.

31. Perez HL, Cardarelli PM, Deshpande S, Gangwar S, Schroeder GM, Vite GD and Borzilleri RM: Antibody-drug conjugates: Current status and future directions. Drug Discov Today 19: 869-881, 2014.

32. Berezhnaya NM, Belova OB, Vinnichuk YD and Tarutinov VI: Expression of E-cadherin in drug resistant human breast cancer cells and their sensitivity to lymphokine-activated lymphocytes action. Exp Oncol 31: 242-245, 2009.

33. Chen X, Wang Y, Xia H, Wang Q, Jiang X, Lin Z, Ma Y, Yang Y and $\mathrm{Hu} \mathrm{M}$ : Loss of E-cadherin promotes the growth, invasion and drug resistance of colorectal cancer cells and is associated with liver metastasis. Mol Biol Rep 39: 6707-6714, 2012.

34. Lazarova DL and Bordonaro M: Vimentin, colon cancer progression and resistance to butyrate and other HDACis. J Cell Mol Med 20: 989-993, 2016

35. Arumugam T, Ramachandran V, Fournier KF, Wang $\mathrm{H}$, Marquis L, Abbruzzese JL, Gallick GE, Logsdon CD, McConkey DJ and Choi W: Epithelial to mesenchymal transition contributes to drug resistance in pancreatic cancer. Cancer Res 69: 5820-5828, 2009.

36. Li Y, VandenBoom TG II, Kong D, Wang Z, Ali S, Philip PA and Sarkar FH: Up-regulation of miR-200 and let-7 by natural agents leads to the reversal of epithelial-to-mesenchymal transition in gemcitabine-resistant pancreatic cancer cells. Cancer Res 69: 6704-6712, 2009.
37. Xie CG, Wei SM, Chen JM, Xu XF, Cai JT, Chen QY and Jia LT: Down-regulation of GEP100 causes increase in E-cadherin levels and inhibits pancreatic cancer cell invasion. PLoS One 7: e37854, 2012

38. Gradiz R, Silva HC, Carvalho L, Botelho MF and Mota-Pinto A: MIA PaCa-2 and PANC-1-pancreas ductal adenocarcinoma cell lines with neuroendocrine differentiation and somatostatin receptors. Sci Rep 6: 21648, 2016.

39. Teixidó C, Marés R, Aracil M, Ramón y Cajal S and Hernández-Losa J: Epithelial-mesenchymal transition markers and HER 3 expression are predictors of elisidepsin treatment response in breast and pancreatic cancer cell lines. PLoS One 8: e53645, 2013

40. Nishino H, Takano S, Yoshitomi H, Suzuki K, Kagawa S, Shimazaki R, Shimizu H, Furukawa K, Miyazaki M and Ohtsuka M: Grainyhead-like 2 (GRHL2) regulates epithelial plasticity in pancreatic cancer progression. Cancer Med 6: 2686-2696, 2017

41. Lafitte M, Moranvillier I, Garcia S, Peuchant E, Iovanna J, Rousseau B, Dubus P, Guyonnet-Dupérat V, Belleannée G, Ramos J, et al: FGFR3 has tumor suppressor properties in cells with epithelial phenotype. Mol Cancer 12: 83, 2013.

42. Burris HA III, Moore MJ, Andersen J, Green MR, Rothenberg ML, Modiano MR, Cripps MC, Portenoy RK, Storniolo AM, Tarassoff $\mathrm{P}$, et al: Improvements in survival and clinical benefit with gemcitabine as first-line therapy for patients with advanced pancreas cancer: A randomized trial. J Clin Oncol 15: 2403-2413, 1997.

43. Teague A, Lim KH and Wang-Gillam A: Advanced pancreatic adenocarcinoma: A review of current treatment strategies and developing therapies. Ther Adv Med Oncol 7: 68-84, 2015.

44. Huang ZQ and Buchsbaum DJ: Monoclonal antibodies in the treatment of pancreatic cancer. Immunotherapy 1: 223-229, 2009.

45. Chames P, Kerfelec B and Baty D: Therapeutic antibodies for the treatment of pancreatic cancer. ScientificWorldJournal 10: $1107-1120,2010$

46. Luedke E, Jaime-Ramirez AC, Bhave N and Carson WE III: Monoclonal antibody therapy of pancreatic cancer with cetuximab: Potential for immune modulation. J Immunother 35: 367-373, 2012.

47. Harder J, Ihorst G, Heinemann V, Hofheinz R, Moehler M, Buechler P, Kloeppel G, Röcken C, Bitzer M, Boeck S, et al: Multicentre phase II trial of trastuzumab and capecitabine in patients with HER 2 overexpressing metastatic pancreatic cancer. Br J Cancer 106: 1033-1038, 2012.

48. Forero-Torres A, Infante JR, Waterhouse D, Wong L, Vickers S, Arrowsmith E, He AR, Hart L, Trent D, Wade J, et al: Phase 2, multicenter, open-label study of tigatuzumab (CS-1008), a humanized monoclonal antibody targeting death receptor 5 , in combination with gemcitabine in chemotherapy-naive patients with unresectable or metastatic pancreatic cancer. Cancer Med 2: 925-932, 2013.

49. Philip PA, Goldman B, Ramanathan RK, Lenz HJ, Lowy AM, Whitehead RP, Wakatsuki T, Iqbal S, Gaur R, Benedetti JK and Blanke CD: Dual blockade of epidermal growth factor receptor and insulin-like growth factor receptor-1 signaling in metastatic pancreatic cancer: Phase Ib and randomized phase II trial of gemcitabine, erlotinib, and cixutumumab versus gemcitabine plus erlotinib (SWOG S0727). Cancer 120: 2980-2985, 2014.

50. Van Cutsem E, Vervenne WL, Bennouna J, Humblet Y, Gill S, Van Laethem JL, Verslype C, Scheithauer W, Shang A, Cosaert J and Moore MJ: Phase III trial of bevacizumab in combination with gemcitabine and erlotinib in patients with metastatic pancreatic cancer. J Clin Oncol 27: 2231-2237, 2009.

51. Karanikas M, Esempidis A, Chasan ZT, Deftereou T, Antonopoulou M, Bozali F, Amarantidis K and Man YG: Pancreatic cancer from molecular pathways to treatment opinion. J Cancer 7: 1328-1339, 2016.

52. Slingluff CL Jr: The present and future of peptide vaccines for cancer: Single or multiple, long or short, alone or in combination? Cancer J 17: 343-350, 2011.

This work is licensed under a Creative Commons Attribution-NonCommercial-NoDerivatives 4.0 International (CC BY-NC-ND 4.0) License. 